\title{
Correlation Between Electron Capture Negative Chemical Ionization Mass Spectrometric Fragmentation and Calculated Internal Energies for Polychlorinated Biphenyls
}

\author{
John Greaves, Ellen Harvey, and William G. MacIntyre \\ Virginia Institute of Marine Science, School of Marine Science, College of William and Mary, Gloucester Point, \\ Virginia, USA
}

\begin{abstract}
Correlations between molecular structure and fragmentation observed in electron capture negative chemical ionization mass spectra (moderator gas = methane) of 49 selected tetrachlorinated, pentachlorinated, and hexachlorinated biphenyls have been investigated by using molecular modeling. The semiempirical general molecular orbital program MOPAC was used to calculate molecular properties for biphenyl and the 209 polychlorinated biphenyls. The mass spectrometric ionization and fragmentation processes were found to be linked to the number of chlorine atoms present on the biphenyl, and to the number of those chlorine atoms in the ortho $\left(2,2^{\prime}, 6\right.$, and $\left.6^{\prime}\right)$ positions. The intensity of molecular ions increased with the number of chlorine atoms present, but this was counteracted by enhanced fragmentation as the number of ortho position chlorine atoms increased. The molecular parameters that were most closely linked with the number of ortho chlorine atoms were the twist angle between the phenyl rings and the energy of the lowest unoccupied molecular orbital (LUMO). It is suggested that fragmentation occurs when the energy of the ionizing electron exceeds the energy difference between the LUMO and LUMO +1 orbitals. ( $\mathrm{Am}$ Soc Mass Spectrom 1994, 5, 44-52)
\end{abstract}

$\mathrm{E}$ lectron capture negative chemical ionization (ECNCI) mass spectrometry is particularly useful in environmental chemistry because the technique is sensitive and selective for organohalogen pollutants. In the study of these environmental pollutants there is the need to identify and quantify the components of complex mixtures. The toxicity of specific components of these mixtures is well recognized, for example, 2,3,7,8-tetrachlorodibenzo-p-dioxin among the polychlorodioxins. Unambiguous identification of the components of mixtures is therefore of particular importance to the environmental chemist. Such mixtures frequently contain positional isomers which are difficult or impossible to identify by mass spectrometry. Other techniques such as proton NMR and X-ray crystallography are capable of providing isomeric structural information but require much larger amounts of pure material. Such quantities and purity are not usually available from environmental samples. However, there are a limited number of reports on the use of ECNCI to obtain structural information on some isomeric compounds that is not obtainable by other mass spectrometric methods. Reports on this application of ECNCI include: relating the fragmentation of polychlo-

Address reprint requests to John Greaves, Department of Chemistry, University of California, Irvinc, Irvine, CA 92717. rinated biphenyls $(\mathrm{PCB})$ to the number and position of the substituent chlorine atoms $[1,2]$; demonstrating the systematic variation in the expulsion of $[\mathrm{Br}]^{-}$ions from polybrominated biphenyls [3]; revealing the presence of a hitherto undetected PCB congener in Aroclor 1260 [4]; and structure-specific fragmentation in chlorinated bicyclics, chlorophenols, and PCB [5] and the polychlorodibenzo-p-dioxins [6]. Tandem mass spectrometry in the oxygen-enhanced NCI mode has also provided structural information on PCB. In this case, there were specific variations in the loss of $\mathrm{HCl}$ in the collision-induced dissociation spectra [7]. Earlier research by Dougherty et al. $[8,9]$ investigated the NCI process. However, these researchers were in general using combinations of reagent gases which resulted in predominantly ion-molecule reactions occurring, such as the formation of oxygen and chloride adducts, as opposed to the EC mode reactions being considered in the current report.

Reaction processes in an ECNCI source are incompletely understood, although, for chlorinated organic molecules, the capture of thermal electrons appears to be the dominant process [10]. It is reasonable to assume that the ionization of these compounds in ECNCI is related to the stabilization of an electron in an unoccupied molecular orbital. Thus, ECNCI spectra may be related to the distributions and energies of 
electrons in the ion source of the mass spectrometer and to the energies of the molecular orbitals of the halogenated organic molecules. In studies on ECNCI processes, Stemmler et al. [11, 12] reported on the importance of maintenance of source conditions. In addition, the variation in ECNCI spectra of both chlorinated and nonchlorinated compounds was investigated by using a wide range of quadrupole and magnetic instruments. They found that, in general, with appropriate care, spectra obtained were consistent from instrument to instrument, except in the case of the Hewlett Packard Model 5985, which gave consistently different spectra for chlorinated compounds, with enhanced molecular ions and reduced intensity of $[\mathrm{Cl}]^{-}$ ions.

The present study is based on the idea that a more thorough understanding of ECNCI as it relates to the molecular structure of closely related analytes will provide insights into the ECNCI fragmentation process and thereby assist in structure determination. Therefore, possible correlations between ECNCI spectra and molecular properties, determined by molecular modeling, have been investigated for a set of $\mathrm{PCB}$ congener molecules containing subsets that are structural isomers. Spectra of each of these PCB congeners have been obtained since ECNCI spectra of most congeners were not available in the literature. The authors considered it important to conduct experimentation in a manner similar to that generally used for the analysis of environmental samples. Therefore, the instrumentation used was not modified, the mass range scanned was $m / z: 100-400$, and the fragmentations considered were those most closely related to the molecular ion.

Determination of correlations between the fragmentation observed in the spectra obtained with molecular structural and electronic characteristics requires information on bond lengths, bond angles, molecular orbital energies, and thermodynamic properties. Experimental thermodynamic data is unavailable for the individual PCB congeners, and would be prohibitively costly and difficult to measure. Fortunately, molecular quantum mechanical calculation computer programs (molecular modeling) can provide estimates of the values of these properties for the PCB congeners, which can then be correlated with information from the ECNCI spectra.

Molecular model results have been used previously in the examination of the ECNCI mass spectra of several polychlorodibenzo-p-dioxins [5] and polychlorodibenzofurans [13]. These authors used complete neglect of differential overlap methods for the calculation of orbital energies, and found correlations between fragmentation, calculated as branching ratios, and the lowest unoccupied molecular orbital (LUMO) and LUMO +2 energies (where LUMO $+n=$ the orbital $n$ levels above the LUMO). They also observed that energy-to-branching ratio correlations were possibly influenced by regiospecific chlorine loss. The same laboratory [13], using both polychlorodibenzo-pdioxins and polychlorodibenzofurans, showed that $[\mathrm{M}]^{-}$ions were most intense for specific LUMO energies.

The current work used modified neglect of differential overlap molecular model calculations to predict energy levels and molecular geometries for biphenyl and all 209 PCB congeners. Results obtained were then correlated statistically with the observed ECNCI mass spectra of a selected group of 49 PCB congeners.

Significant correlations between spectra and model results may contribute toward several goals. (1) Information may be obtained that contributes to the elucidation of the $\mathrm{ECNCI}$ reaction processes, particularly as they apply to PCB and other chlorinated organic molecules. (2) A tentative identification of a PCB congener may be predicted from the combination of observed mass spectral fragmentation data and molecular modeling results for the compound assumed present. If the model results predict the observed spectrum, then tentative identification of the congener is obtained without reference to spectra libraries. This is important because ECNCI spectra can be somewhat instrument-specific [12] and little library data are currently available. It would be desirable to further confirm the putative model-based identification of the unknown by matching its mass spectrum with that of a suitable reference standard measured under the same conditions. (3) The ultimate goal of this research is to use molecular models to unequivocally identify PCB congeners by establishing unique relations between the observed ECNCI mass spectrum and model results. This is not attainable with the model used here (MOPAC), but the present work is a step toward that goal.

\section{Experimental}

PCB congeners were purchased from Ultra Scientific Inc. (Providence, RI). Congeners obtained were IUPAC system numbers $40,42,44,47,49,50,52,53,54,58,60$, $61,66,69,70,72,75,77,78,80$ for tetrachlorobiphenyls; $88,95,100,101,104,105,112,116,118,119,121,124$, 125, 126, 127 for pentachlorobiphenyls; and 133, 136, $138,141,143,151,153,154,155,156,158,159,167,169$ for hexachlorobiphenyls. These compounds were selected to include a wide range of structures, particularly with respect to substitution in the $2,2^{\prime}, 6,6^{\prime}, 4$, and $4^{\prime}$ positions. The choice of tetrachlorobiphenyls, pentachlorobiphenyls, and hexachlorubiphenyls was based on preliminary observations of the extent of fragmentation in these sets of homologs.

Congeners were each dissolved in hexane at a concentration of $20 \mathrm{ng} \mu \mathrm{L}^{-1}$, and analyzed by gas chromatography-mass spectrometry (GC-MS) on an Extrel Model ELQ 400-2 quadrupole mass spectrometer (Extrel Corp., Pittsburgh, PA). A $\mathbf{3 0} \mathrm{m}$ long $\times \mathbf{0 . 3 3} \mathrm{mm}$ i.d. fused silica column with a $0.25 \mu \mathrm{m}$ cross-linked $5 \%$ 
phenyl-95\% methyl silicone liquid phase (DB-5, J \& W Scientific, Folsom, CA) was routed directly to the source of the mass spectrometer through an interface held at $250{ }^{\circ} \mathrm{C}$. The GC-MS source was maintained at $100{ }^{\circ} \mathrm{C}$ and operated in the ECNCI mode with methane as the moderator gas at a source pressure of 0.7 torr $(700 \mu \mathrm{m})$. The source pressure was monitored with a thermocouple gauge via a tube that passed through the flange of the instrument and was sealed against the source block with a vespel fitting. The methane inlet was coaxial with the GC column. Initial electron energy was $300 \mathrm{eV}$. The scan range was 100 to $400 \mathrm{u}$ at $500 \mathrm{u} \mathrm{s}^{-1}$.

Molecular model application was constrained by computer requirements. Molecules containing 20 or more atoms are currently too large for quantum mechanical modeling by ab initio methods on a routine basis. Calculations for one $\mathrm{PCB}$ congener would require excessive run time on a current super computer. Accordingly, a semiempirical method with a more practical run time on a mini computer was selected, following discussion with staff of the Quantum Chemistry Program Exchange (QCPE), Indiana University. Bloomington, Indiana. The MOPAC program (Version 5.0) used to calculate molecular properties of the PCB congeners was obtained from QCPE, and was operated on a DEC VAX computer (Digital Equipment Corp., Maynard, MA). For biphenyl and all 209 PCB congeners, the MOPAC program was run using the AM1 Hamiltonian to determine orbital energies, molecular geometries, and other parameters. A constant format for data entry was used in which the only changes made were substitutions of chlorine and hydrogen into the matrix as appropriate for each congener. This removed the possibility of data entry format influencing the MOPAC results.

\section{Results}

\section{Mass Spectra}

ECNCI spectra of the $49 \mathrm{PCB}$ congeners varied systematically with the number of chlorine atoms present and with the positions of the chlorine substitutions. The spectra showed substantial qualitative and quantitalive variation in fragmentation. Spectra were comlprised of combinations of $\left[\mathrm{M}^{-},[\mathrm{M}-\mathrm{H}]^{-},\left[\mathrm{M}-\mathrm{Cl}^{-}\right.\right.$, and $\left[\mathrm{M}-2 \mathrm{Cl}^{-}\right.$ions. The scan range chosen was based on that used in the practical analysis of enviromunental samples, thus data were collected on the molecular ion and its immediate fragments and not on the $[\mathrm{Cl}]^{-}$ions. The occurrence and intersity of the $[\mathrm{M}]^{-}$ions increased with the number of chlorine atoms on the molecule. Thus, $[\mathrm{M}]^{-}$was the base peak in spectra of 9 of 20 tetrachlorobiphenyl congeners, 12 of 15 pentachlorobiphenyl congeners, and 12 of 14 hexachlorobiphenyl congeners. Data for the selected congeners, including intensities of ions and the most relevant model-generated parameters, are given in Table 1. The fragmentation data parallel that obtained by ErhardtZabik et al. [5], who found increasing molecular ion intensities for the PCB up to the octochloro level and some indication that fragmentation was structurespecific. These authors noted that the molecular ion intensity became reduced for a nonachlorobiphenyl and decachlorobiphenyl, a situation that has also been noted for the polychlorodibenzo-p-dioxins but is less obvious for the polychlorodibenzofurans [13]. Erhardt-Zabik et al. [5] reasoned that the reduction in molecular ion intensity is related to stereochemistry and degrees of freedom of the most highly substituted organochlorines.

The influence of chlorine atom position on spectra was marked, as illustrated in Figure 1, which presents spectra of five pentachlorobiphenyls with IUPAC numbers $127,124,121,100$ and 104 . In this set of isomers, the number of chlorine atoms in the ortho $\left(2,2^{\prime}, 6\right.$ or $\left.6^{\prime}\right)$ positions increases from zero to four. Fragmentation increases with number of ortho chlorine atoms. IUPAC $\$ 127$ has no ortho chlorine atoms and its spectrum consists almost entirely of the molecular ion cluster. IUPAC $\# 104$ has chlorine atoms at all four ortho positions, there is no obvious molecular ion, and the spectrum is comprised of $\left[\mathrm{M}-\mathrm{H}^{-},\left[\mathrm{M}-\mathrm{Cl}^{-}\right.\right.$, and $\left[\mathrm{M}-2 \mathrm{Cl}^{-}\right.$ions. The other spectra in Figure 1 illustrate the extent of fragmentation as the number of ortho position chlorine atoms increases.

The overall pattern for the congeners studied is described in Table 2, which presents spectral data that have been averaged and normalized separately for each level of chlorination and each number of ortho position chlorine atoms. The standard deviations for this derived spectral information were typically in the $30 \%$ range. Deviation data could not be obtained where there werc less than three congeners involved or where all intensities were $100 \%$. The opposing effects of increased prevalence of the molecular ion with increasing number of chlorine atoms, and of more extensive fragmentation as the ortho positions become occupied with chlorine atoms, are apparent from these data. For compounds where $\left[\mathrm{M}-\mathrm{II}^{-}{ }^{-}\right.$was more intense than the molecular ion, the intensity of the latter was calculated from the isotope distribution.

Pussible sample size effects on spectra were examined by injections of congeners in various amounts over the range of $10-60 \mathrm{ng}$. This was done for two congeners, $2,2^{\prime}, 4,4^{3}, 6,6^{\prime}$-hexachlorobiphenyl $(\$ 155)$ and $2,2^{\prime}, 3,4,4^{\prime}, 5^{\prime}$-hexachlorobiphenyl ( $\left.\$ 138\right)$, in which the base peaks were the $\left[\mathrm{M}-\mathrm{Cl}^{-}\right.$and $[\mathrm{M}]^{-}$ions, respectively. The variation in the fragment ion was monitored; for the $[\mathrm{M}-\mathrm{H}]^{-}$ion of $\# 155$ it was $30.3 \% \pm$ $6.6 \%(\mathrm{n}=7)$ of the $\left[\mathrm{M}-\mathrm{Cl}^{-}\right.$base peak, and for the $[\mathrm{M}-\mathrm{Cl}]^{-}$ion of $\# 138$ it was $32.4 \% \pm 9.7 \%(n=7)$ of the $[\mathrm{M}]^{-}$base peak. There was no systematic variation in the spectra with increasing sample size. These re- 
Table 1. Data for 49 selected congeners from molecular modeling and $\mathrm{ECNCI}$ fragmentation

\begin{tabular}{|c|c|c|c|c|c|c|c|c|c|c|}
\hline $\begin{array}{l}\text { IUPAC } \\
\text { number }\end{array}$ & Structure & $\begin{array}{l}\text { Calculated } \\
\text { heat of } \\
\text { formation } \\
\text { (kcal } / \mathrm{mol} \text { ) }\end{array}$ & $\begin{array}{c}\text { Calculated } \\
\text { twist angle } \\
\text { (degrees) }\end{array}$ & $\begin{array}{c}\text { Calculated } \\
\text { LUMO } \\
(\mathrm{eV})\end{array}$ & $\begin{array}{l}\text { Calculated } \\
\text { LUMO + } 1 \\
(\mathrm{eV})\end{array}$ & $\begin{array}{c}\text { Calculated } \\
\text { LUMO + } 2 \\
(\mathrm{eV})\end{array}$ & $\begin{array}{c}{[\mathrm{M}]^{-}} \\
\%\end{array}$ & $\begin{array}{c}{[M-H]^{-}} \\
\%\end{array}$ & $\begin{array}{c}{\left[\mathrm{M}-\mathrm{Cl}^{-}\right.} \\
\%\end{array}$ & {$\left[\mathrm{M}-\underset{\%}{2 \mathrm{Cl}]^{-}}\right.$} \\
\hline 40 & $22^{\prime} 33^{\prime}$ & 26.69 & 70.65 & -0.425 & -0.204 & -0.195 & 26 & 100 & 16 & 9 \\
\hline 42 & $22^{\prime} 34^{\prime}$ & 25.43 & 71.21 & -0.488 & -0.215 & -0.135 & 25 & 100 & 32 & 28 \\
\hline 44 & $22^{\prime} 35^{\prime}$ & 25.37 & 72.55 & -0.441 & -0.216 & -0.202 & 21 & 100 & 21 & 10 \\
\hline 47 & $22^{\prime} 44^{\prime}$ & 24.18 & 70.69 & -0.554 & -0.177 & -0.143 & 28 & 86 & 100 & 9 \\
\hline 49 & $22^{\prime} 45^{\prime}$ & 24.14 & 72.82 & -0.499 & -0.252 & -0.141 & 22 & 100 & 81 & 33 \\
\hline 50 & $22^{\prime} 46^{\prime}$ & 26.11 & 84.03 & -0.469 & -0.337 & -0.031 & 19 & 100 & 75 & 0 \\
\hline 52 & $22^{\prime} 55^{\prime}$ & 24.15 & 69.49 & -0.507 & -0.255 & -0.191 & 25 & 73 & 100 & 39 \\
\hline 53 & $22^{\prime} 56^{\prime}$ & 25.48 & 85.92 & -0.283 & -0.218 & -0.047 & 15 & 100 & 53 & 38 \\
\hline 54 & $22^{\prime} 66^{\prime}$ & 27.02 & 85.99 & -0.210 & -0.127 & -0.108 & 19 & 100 & 28 & 15 \\
\hline 58 & $233^{\prime} 5^{\prime}$ & 24.24 & 56.27 & -0.622 & -0.300 & -0.220 & 100 & 67 & 28 & 7 \\
\hline 60 & $2344^{\prime}$ & 25.41 & 54.10 & -0.729 & -0.419 & -0.044 & 100 & 24 & 17 & 11 \\
\hline 61 & 2345 & 27.64 & 55.23 & -0.751 & -0.559 & -0.213 & 100 & 72 & 50 & 0 \\
\hline 66 & $23^{\prime} 44^{\prime}$ & 23.73 & 54.84 & -0.722 & -0.232 & -0.142 & 38 & 100 & 15 & 14 \\
\hline 69 & $23^{\prime} 46$ & 25.09 & 71.58 & -0.610 & -0.430 & -0.011 & 22 & 100 & 63 & 22 \\
\hline 70 & $23^{\prime} 4^{\prime} 5$ & 23.69 & 53.72 & -0.697 & -0.310 & -0.131 & 60 & 100 & 42 & 27 \\
\hline 72 & $23^{\prime} 55^{\prime}$ & 22.88 & 55.13 & -0.666 & -0.308 & -0.227 & 100 & 55 & 30 & 5 \\
\hline 75 & $244 / 6$ & 24.76 & 77.60 & -0.581 & -0.438 & -0.079 & 4 & 20 & 100 & 6 \\
\hline 77 & $33^{\prime} 44^{\prime}$ & 22.77 & 41.92 & -0.844 & -0.231 & -0.223 & 100 & 33 & 4 & 0 \\
\hline 78 & $33^{\prime} 45$ & 23.37 & 41.49 & -0.827 & -0.403 & -0.091 & 100 & 37 & 8 & 0 \\
\hline 80 & $33^{\prime} 55^{\prime}$ & 21.11 & 41.30 & -0.804 & -0.335 & -0.313 & 100 & 32 & 2 & 0 \\
\hline 88 & $22^{\prime} 346$ & 22.46 & 88.39 & -0.661 & -0.557 & -0.116 & 71 & 74 & 100 & 0 \\
\hline 95 & $22^{\prime} 35^{\prime} 6$ & 20.54 & 86.73 & -0.517 & -0.438 & -0.324 & 28 & 93 & 100 & 55 \\
\hline 100 & $22^{\prime} 44^{\prime} 6$ & 19.62 & 84.90 & -0.581 & -0.437 & -0.347 & 22 & 100 & 55 & 7 \\
\hline 101 & $22^{\prime} 455^{\prime}$ & 19.15 & 73.18 & -0.674 & -0.408 & -0.341 & 100 & 56 & 50 & 13 \\
\hline 104 & $22^{\prime} 466^{\prime}$ & 20.98 & 87.95 & -0.485 & -0.338 & -0.273 & 12 & 61 & 100 & 25 \\
\hline 105 & $233^{\prime} 44^{\prime}$ & 20.16 & 54.37 & -0.856 & -0.495 & -0.219 & 100 & 24 & 16 & 7 \\
\hline 112 & $233^{\prime} 56$ & 21.43 & 75.54 & -0.749 & -0.679 & -0.079 & 100 & 24 & 23 & 1 \\
\hline 116 & 23456 & 25.04 & 78.63 & -0.809 & -0.799 & -0.102 & 100 & 20 & 29 & 0 \\
\hline 118 & $23^{\prime} 44^{\prime} 5$ & 18.73 & 54.41 & -0.891 & -0.497 & -0.223 & 100 & 33 & 16 & 6 \\
\hline 119 & $23^{\prime} 44^{\prime} 6$ & 19.62 & 71.04 & -0.731 & -0.509 & -0.256 & 100 & 42 & 38 & 44 \\
\hline 121 & $23^{\prime} 45^{\prime} 6$ & 18.85 & 77.65 & -0.672 & -0.507 & -0.230 & 100 & 43 & 29 & 8 \\
\hline 124 & $23^{\prime} 455^{\prime}$ & 18.96 & 59.50 & -0.807 & -0.404 & -0.383 & 100 & 22 & 8 & 0 \\
\hline 125 & $2^{\prime} 3456^{\prime}$ & 20.64 & 76.93 & -0.576 & -0.354 & -0.303 & 100 & 28 & 17 & 0 \\
\hline 126 & $33^{\prime} 44^{\prime} b$ & 18.12 & 39.19 & -1.001 & -0.491 & -0.294 & 100 & 24 & 3 & 0 \\
\hline 127 & $33^{\prime} 455^{\prime}$ & 17.29 & 41.51 & -0.967 & -0.489 & -0.391 & 100 & 19 & 3 & 0 \\
\hline 133 & $22^{\prime} 33^{\prime} 55^{\prime}$ & 14.78 & 72.10 & -0.763 & -0.570 & -0.555 & 100 & 21 & 16 & 2 \\
\hline 136 & $22^{\prime} 33^{\prime} 66^{\prime}$ & 17.10 & 86.48 & -0.527 & -0.500 & -0.439 & 37 & 100 & 64 & 30 \\
\hline 138 & $22^{\prime} 344^{\prime} 5^{\prime}$ & 15.48 & 74.56 & -0.788 & -0.527 & -0.479 & 100 & 32 & 23 & 1 \\
\hline 141 & $22^{\prime} 3455^{\prime}$ & 15.92 & 72.29 & -0.822 & -0.651 & -0.427 & 100 & 20 & 30 & 5 \\
\hline 143 & $22^{\prime} 3456^{\prime}$ & 17.37 & 79.33 & -0.702 & -0.556 & -0.372 & 100 & 70 & 74 & 5 \\
\hline 151 & $22^{\prime} 355^{\prime} 6$ & 16.02 & 88.29 & -0.745 & -0.664 & -0.410 & 100 & 65 & 51 & 7 \\
\hline 153 & $22^{\prime} 44^{\prime} 55^{\prime}$ & 14.20 & 70.97 & -0.857 & -0.558 & -0.474 & 100 & 38 & 12 & 0 \\
\hline 154 & $22^{\prime} 44^{\prime} 56^{\prime}$ & 14.63 & 82.86 & -0.694 & -0.556 & -0.500 & 100 & 38 & 77 & 14 \\
\hline 155 & $22^{\prime} 44^{\prime} 66^{\prime}$ & 15.08 & 87.05 & -0.613 & -0.554 & -0.423 & 6 & 25 & 100 & 11 \\
\hline 156 & $233^{\prime} 44^{\prime} 5$ & 1561 & 55.61 & -1.011 & -0.734 & -0.313 & 100 & 35 & 7 & 0 \\
\hline 158 & $233^{\prime} 44^{\prime} 6$ & 16.14 & 72.87 & -0.880 & -0.739 & -0.356 & 100 & 34 & 18 & 0 \\
\hline 159 & $233^{\prime} 455^{\prime}$ & 14.86 & 55.71 & -1.004 & -0.737 & -0.367 & 100 & 15 & 8 & 0 \\
\hline 167 & $23^{\prime} 44^{\prime} 55^{\prime}$ & 14.07 & 53.83 & -1.022 & -0.572 & -0.471 & 100 & 27 & 5 & 0 \\
\hline 169 & $33^{\prime} 44^{\prime} 55^{\prime}$ & 13.38 & 42.24 & -1.119 & -0.564 & -0.541 & 100 & 25 & 3 & 0 \\
\hline
\end{tabular}




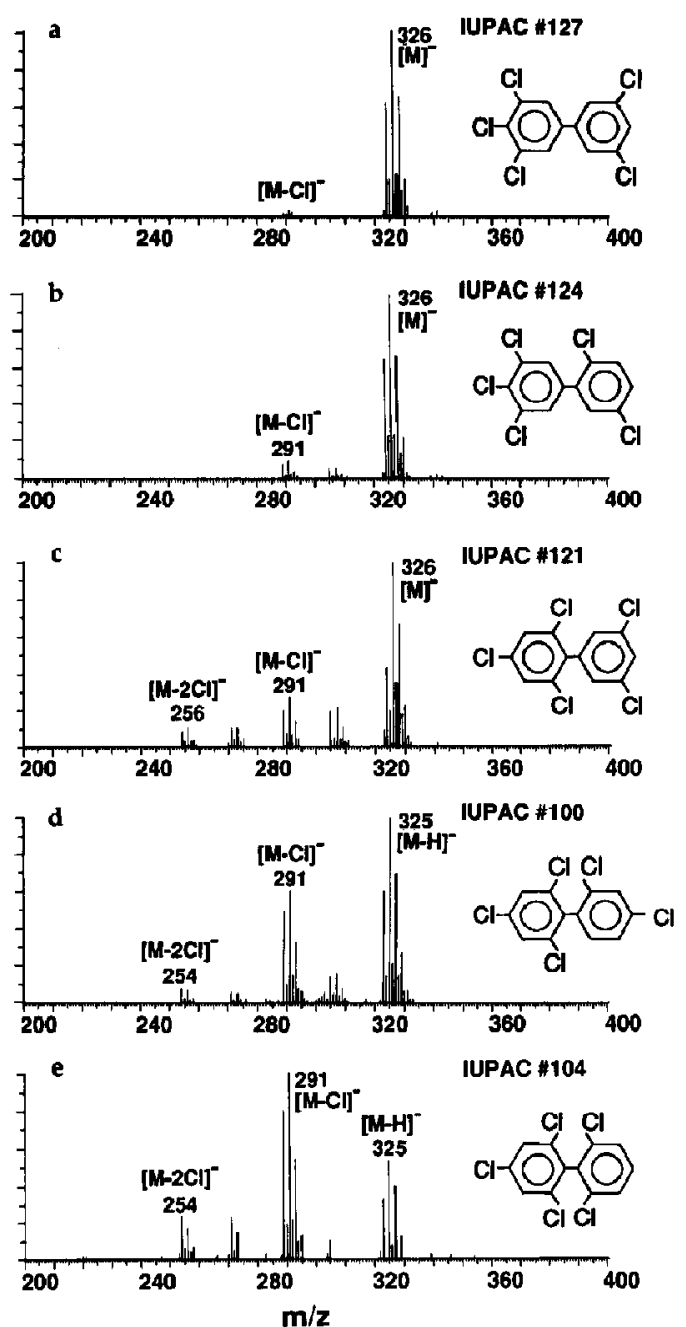

Figure 1. ECNCI mass spectra for five pentachlorobiphenyls (IUPAC numbers 127, 124, 121, 100, 104) illustrating association of fragmentation with position of substituent chlorine atoms. Sections $a, b, c$, d, e show spectra of pentachlorobiphenyls with 0 , $1,2,3,4$ ortho position chlorine atoms, respectively.

sults indicated that, at the nanogram level, sample size did not affect fragmentation.

\section{Molecular Modeling}

PCB property data generated by MOPAC included heat of formation, twist angle between the phenyl rings, and the energies of the molecular orbitals. Because of the assumptions made, the data reflect in vacuo conditions at $0 \mathrm{~K}$. Information derived from the program was intuitively reasonable. Heats of formation were inversely related to the number of chlorine atoms substituent on the biphenyl, decreasing from $47.6 \mathrm{kcal} \mathrm{mol}^{-1}$ for biphenyl to $2.4 \mathrm{kcal} \mathrm{mol}{ }^{-1}$ for decachlorobiphenyl. This is illustrated in Figure 2. The
Table 2. Distribution of intensities of fragments of PCB in ECNCI spectra*

\begin{tabular}{|c|c|c|c|c|c|}
\hline \multicolumn{2}{|c|}{$\begin{array}{l}\text { Number } \mathrm{Cl} \text { Number of } \\
\text { in ortho congeners } \\
\text { position averaged }\end{array}$} & \multirow[t]{2}{*}{ [M] $^{-}$} & \multicolumn{3}{|c|}{$[\mathrm{M}-\mathrm{H}]^{-}[\mathrm{M}-\mathrm{Cl}]^{-}[\mathrm{M}-2 \mathrm{Cl}]$} \\
\hline \multicolumn{5}{|c|}{ Tetrachlorobiphenyls } & \\
\hline & & $m / z 292^{\circ}$ & $m / z 291$ & $m / 2255$ & $m / z 220$ \\
\hline 0 & 3 & 100 & 34 & 5 & - \\
\hline 1 & 6 & 100 & 84 & 36 & 13 \\
\hline 2 & 8 & 25 & 100 & 76 & 23 \\
\hline 3 & 2 & 17 & 100 & 65 & - \\
\hline 4 & 1 & 19 & 100 & 28 & 15 \\
\hline \multicolumn{6}{|c|}{ Pentachlorobiphenyls } \\
\hline & & $\mathrm{m} / \mathrm{z} 326$ & $\mathrm{~m} / \mathrm{z} 325$ & $m / 2291$ & $m / z 254$ \\
\hline 0 & 2 & 100 & 22 & 3 & - \\
\hline 1 & 3 & 100 & 27 & 14 & 3 \\
\hline 2 & 6 & 100 & 37 & 34 & 13 \\
\hline 3 & 3 & 45 & 100 & 95 & 24 \\
\hline 4 & 1 & 12 & 61 & 100 & 25 \\
\hline \multicolumn{6}{|c|}{ Hexachlorabiphenyls } \\
\hline & & $m / z 360$ & $m / 2359$ & $m / 2325$ & $m / z 290$ \\
\hline 0 & 1 & 100 & 25 & 3 & - \\
\hline 1 & 3 & 100 & 26 & 7 & - \\
\hline 2 & 5 & 100 & 29 & 20 & 2 \\
\hline 3 & 3 & 100 & 63 & 67 & 8 \\
\hline 4 & 1 & 22 & 77 & 100 & 26 \\
\hline
\end{tabular}

"Means for multiple congeners calculated and normalized to $100 \%$.

${ }^{a}$ Mass-to-charge ratio value for the most abundant isotope of the cluster.

highest occupied molecular orbital (HOMO), LUMO, $\mathrm{LUMO}+1$, and LUMO +2 energies became more negative as the number of chlorine atom substituents increased. For the HOMO this value dropped from a mean of $-9.08 \mathrm{eV}$ for biphenyl and the monochlorobiphenyls to a mean of $-9.81 \mathrm{eV}$ for the nonachlorobiphenyls and decachlorobiphenyl. Similar decreases

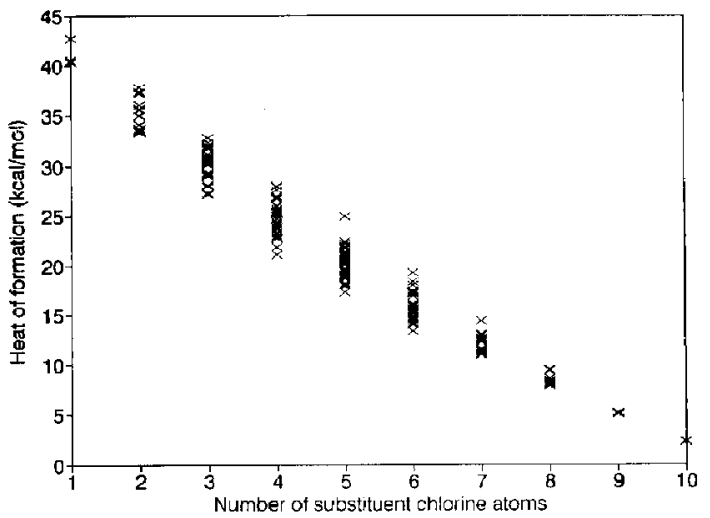

Figure 2. Calculated heats of formation (MOPAC Version 5.0) plotted against number of substituent chlorine atoms for the 209 PCB congeners. 
were calculated for the low unoccupied orbitals: LUMO from $-0.18 \mathrm{eV}$ to $-1.03 \mathrm{eV}$, LUMO +1 from $0.29 \mathrm{eV}$ to $-0.98 \mathrm{eV}$, LUMO +2 from $0.47 \mathrm{eV}$ to $-0.91 \mathrm{eV}$. Data derived by the modeling program, on some parameters, for the 49 selected congeners on which fragmentation information was obtained, are given in Table 1.

Experimental vapor-phase electronic spectra and structural configuration information for PCB, for comparison with values generated by MOPAC, could not be found. Published data for biphenyl give a $43.5 \mathrm{kcal}$ $\mathrm{mol}^{-1}$ heat of formation [14] and a twist angle of approximately $42^{\circ}$ [15]. These values compare favorably with MOPAC results, $47.6 \mathrm{kcal} \mathrm{mol}^{-1}$ and $38.6^{\circ}$, respectively.

The twist angle increased with the number of ortho position chlorine atoms (Figure 3). With no ortho chlorine atoms, the angle was approximately $41^{\circ}$, which is similar to that of biphenyl, as expected. With one ortho chlorine atom, the angle was approximately $56^{\circ}$. This increased to $76^{\circ}, 86^{\circ}$, and $87^{\circ}$ for two, three, and four ortho chlorine atoms, respectively. Thus, chlorine substitutions at three ortho positions set nearly a right angle between the phenyl rings.

Modeling results for homologous sets of PCB indicated that the LUMO was the orbital whose energy was most affected by the progressive restriction of rotation of the phenyl rings caused by an increase in the number of ortho position chlorine atoms. Figure 4 shows this relation for the pentachlorobiphenyls. There is a correlation coefficient of 0.91 for LUMO energy versus number of ortho chlorine atoms. The HOMO or LUMO + 1 energies for the same molecules were not strongly dependent on the number of ortho chlorine atoms. The correlation between LUMO energy and ortho chlorine atoms was weak when all 209 congeners were considered concurrently. However, a plot of the energy difference between LUMO and LUMO + 1 versus the number of ortho position chlorine atoms, given

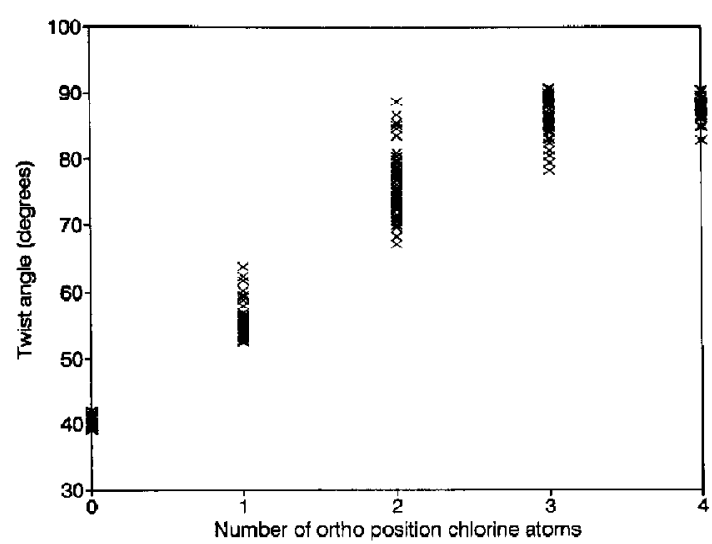

Figure 3. Graph of calculated twist angle between phenyl rings versus number of ortho position chlorine atoms present on the congener (209 congeners used).

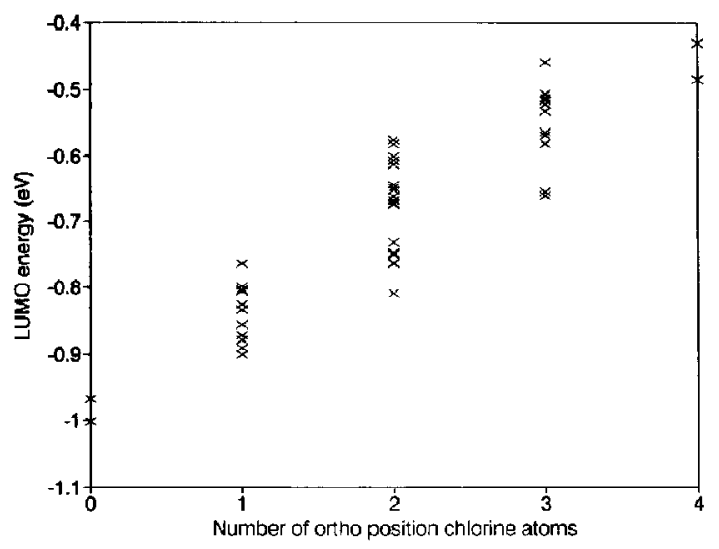

Figure 4. Graph of calculated LUMO energies for pentachlorobiphenyls versus number of ortho position chlorine atoms.

in Figure 5, shows a decrease in the energy difference between the two orbitals as the molecule becomes more twisted. This relation holds for all congeners, as illustrated in Figure 5, and also for homologous congener sets.

\section{Discussion}

Observed PCB congener fragmentation can be correlated with various molecular properties calculated from MOPAC. The $[\mathrm{M}]^{-} /[\mathrm{M}-\mathrm{Cl}]^{-}$and $\left[\mathrm{M}^{-} /[\mathrm{M}-\mathrm{H}]^{-}\right.$ ratios are measures of the extent of molecular ion fragmentation. The larger the ratio, the more molecular ion is present and, therefore, the less the fragmentation that has occurred. Table 3 shows that both the $\log _{10}\left([\mathrm{M}]^{-} /[\mathrm{M}-\mathrm{H}]^{-}\right)$and $\log _{10}\left([\mathrm{M}]^{-} /[\mathrm{M}-\mathrm{Cl}]^{-}\right)$ fragmentation ratios are strongly correlated with several of the molecular model parameters as well as with the number of ortho position chlorine atoms, although

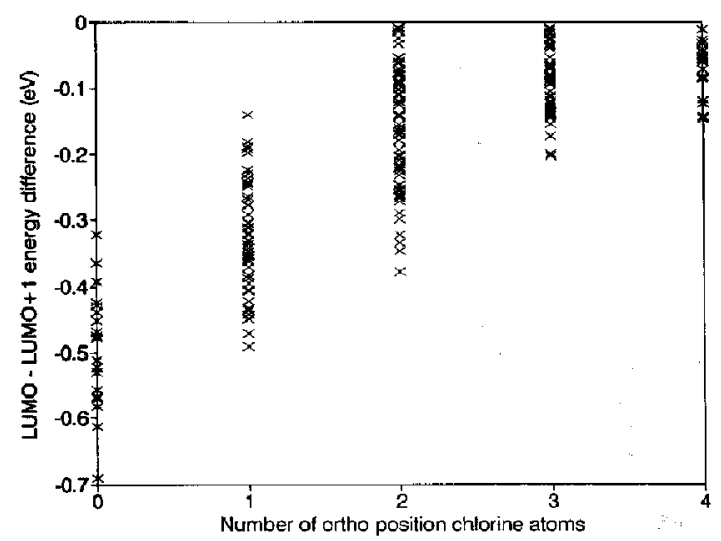

Figure 5. Graph of calculated energy differences between LUMO and LUMO + 1 versus number of ortho position chlorine atoms (209 congeners used). 
Table 3. Regression information on correlations of $\log _{10}\left([\mathrm{M}]^{-} /[\mathrm{M}-\mathrm{H}]^{-}\right)$and $\log _{10}$ $\left([\mathrm{M}]^{-} /[\mathrm{M}-\mathrm{Cl}]^{-}\right)$against molecular structure parameters ${ }^{\mathrm{a}}$

\begin{tabular}{lrrrrrrrrr}
\hline & \multicolumn{3}{c}{$\log _{10}\left(\left[\mathrm{M}^{-} /[\mathrm{M}-\mathrm{H}]^{-}\right)\right.$} & \multicolumn{4}{c}{$\log _{10}\left([\mathrm{M}]^{-} /\left[\mathrm{M}-\mathrm{Cl}^{-}\right)\right.$} \\
\hline \hline LUMO & Slope & Intercept & \multicolumn{1}{c}{$\mathrm{r}^{\mathrm{b}}$} & \multicolumn{1}{c}{$\mathrm{p}^{\mathrm{c}}$} & Slope & Intercept & \multicolumn{1}{c}{$r$} & $\mathrm{p}$ \\
Twist angle & -2.36 & -1.57 & -0.83 & $<0.01$ & -3.02 & -1.77 & -0.78 & $<0.01$ \\
Number of ortho Cl & -0.02 & 1.42 & -0.53 & $<0.01$ & -0.04 & 2.90 & -0.77 & $<0.01$ \\
& -0.30 & 0.62 & -0.60 & $<0.01$ & -0.52 & 1.30 & -0.77 & $<0.01$ \\
\hline
\end{tabular}

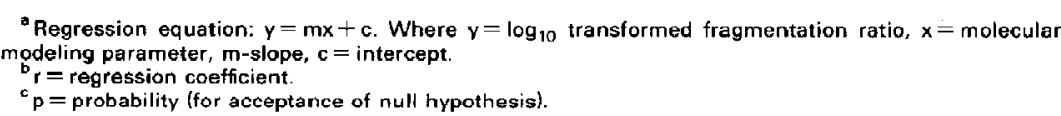

the correlations were more consistent for the $\log _{10}\left([\mathrm{M}]^{-} /\left[\mathrm{M}-\mathrm{Cl}^{-}\right)\right.$ratios. Figure 6 shows the relation between fragmentation, expressed as $\log _{10}\left([\mathrm{M}]^{-} /[\mathrm{M}-\mathrm{Cl}]^{-}\right)$, and LUMO energy. The negative slope of the regression line (Table 3 ) indicates increasing fragmentation with higher LUMO values (the independent variable). Similar graphs are obtained if this fragmentation ratio is plotted against twist angle or the number of ortho position chlorine atoms. This is as would be expected, given the interrelationships between these parameters. Table 3 also shows that the $\log _{10}\left([\mathrm{M}]^{-} /[\mathrm{M}-\mathrm{H}]^{-}\right)$fragmentation ratios are correlated with the same parameters as are the $\log _{10}\left([\mathrm{M}]^{-} /\left[\mathrm{M}-\mathrm{Cl}^{-}\right)\right.$ratios, and that, although the $r$ values are more variable, they are still highly significant. The probability (p) of incorrectly accepting the null hypothesis is less than 0.01 . The variability of the correlations involving the $\log _{10}\left([\mathrm{M}]^{-} /[\mathrm{M}-\mathrm{H}]^{-}\right)$ ratios may indicate that the $[\mathrm{M}-\mathrm{H}]^{-}$ions are being formed by a combination of processes in the ion source. The additional processes may include a wall effect mediated through the retention of free radicals at the surface of the ionization chamber. This type of process has been previously reported as occurring in ECNCI ion sources with the radical species involved reacting with analytes, resulting in hydrogen atom abstraction

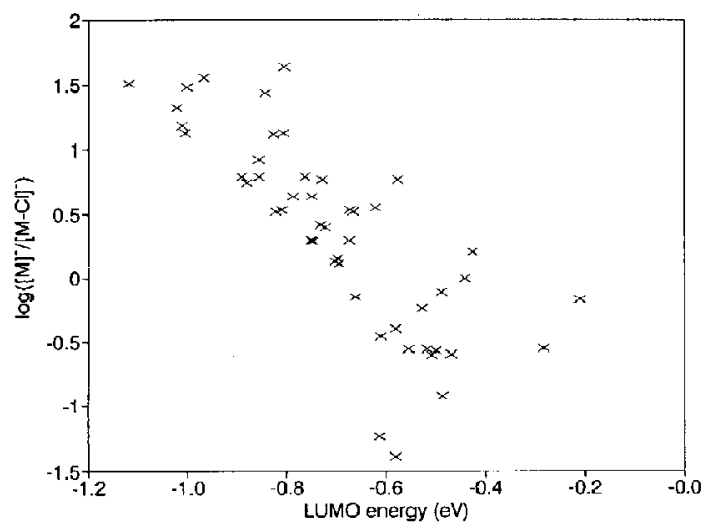

Figure 6. Graph of extent of fragmentation, expressed as $\log _{10}\left([\mathrm{M}]^{-} /[\mathrm{M}-\mathrm{Cl}]^{-}\right)$, versus calculated LUMO energy for 49 $\mathrm{PCB}$ congeners analyzed by ECNCI mass spectrometry.
[16]. Further experimentation with different moderator gases, such as nitrogen, which would eliminate the presence of hydrogen associated with the wall effects, might be useful in explaining this situation, but this is outside the scope of the current research. Documentation of wall effects does not preclude the occurrence of other processes occurring in the gas phase. These include interactions with trace oxygen in the source forming $[\mathrm{M}+\mathrm{O}-\mathrm{Cl}]^{-}$ions or with water to form $[\mathrm{M}+\mathrm{OH}]^{-}$ions [8]. Some formation of $[\mathrm{M}+\mathrm{O}-$ $\mathrm{Cl}^{-}$but not $[\mathrm{M}+\mathrm{OH}]^{-}$was observed in the current work. In addition, there are influences because of the reattachment of auto detached electrons and quantum processes within the source, but the importance of these influences cannot be assessed on the unmodified commercial instrument that was used in these experiments. However, researchers should be aware of the effects of other possible processes on data. The data given in Table 1 also include the intensities of the $[\mathrm{M}-2 \mathrm{Cl}]^{-}$ion. However, because the occurrence of this ion was sporadic, and, therefore, difficult to address, no firm conclusions can be drawn as to the structural and energetic conditions that lead to the loss of two chlorines.

Initial information on the assignment of structural features can be obtained from Table 1. Thus, for the compounds examined, the following can be said: for the tetrachlorobiphenyls with none or one ortho chlorine atom, the base peak was the $\left[\mathrm{M}^{-}\right.$or $[\mathrm{M}-\mathrm{H}]^{-}$ ion; for the pentachlorobiphenyls, an $\left[\mathrm{M}^{-}\right.$ion indicates none, one, or two ortho chlorine atoms; for the hexachlorobiphenyls, only molecules with four ortho chlorine atoms did not have an [M] ${ }^{-}$base peak.

The observed interrelation between number of ortho chlorine atoms, LUMO energy, and twist angle is physically reasonable. Increasing the number of ortho chlorine atoms causes the molecular twist angle to increase (Figure 3). Chlorine atoms have larger radii than hydrogen atoms, and therefore will hinder rotation about the bond linking the two phenyl groups. Once there are three or four ortho chlorine atoms present, a $90^{\circ}$ angle between the two rings is approached.

Since heat of formation is related to molecular energy, it should also be related to the twist angle between phenyl rings. This, however, is not obvious 


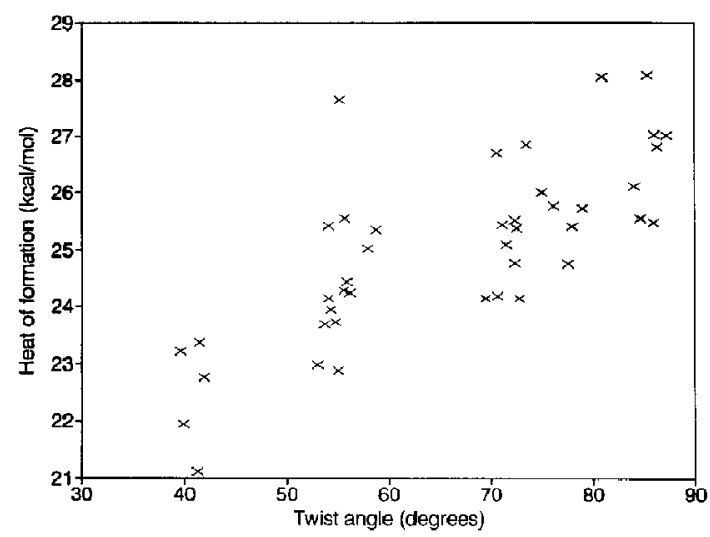

Figure 7. Graph of calculated heats of formation versus calculated twist angles for the tetrachlorobiphenyls.

when the correlation is attempted for all the $\mathrm{PCB}$ congeners because the predominant contribution of the total number of chlorine atoms to the heats of formation overrides the smaller effect of twist angle. If the twist angles of a homologous group of PCB congeners are considered instead, then positive correlations between number of ortho position chlorine atoms and heats of formation are found. This is illustrated for the tetrachlorobiphenyls in Figure 7.

HOMO, LUMO, LUMO + 1 and LUMO +2 energies decrease with increasing number of chlorine atoms. This behavior reflects relative molecular stabilities to ionizing elestrons and, by inference, the extent of fragmentation of molecules containing captured electrons. The increasingly negative energies indicate that $\mathrm{PCB}$ congeners with higher numbers of chlorine atoms should produce more stable negative ions in the source, which will have a lifetime sufficient to reach the mass spectrometer detector. This consideration is supported by observation of increasing abundance of $\mathrm{PCB}$ molecular ions as the number of chlorine atoms increases. Of the orbitals considered, the LUMO would be expected to be the point of stabilization of an ionizing electron and therefore to be linked to the stability of the molecular ion. This was encountered because almost all of the congeners examined having a LUMO more negative than $-0.65 \mathrm{eV}$ had the $[\mathrm{M}]^{-}$ion as the base peak. This is in agreement with Laramée el al. [13], who found intense molecular ions for those polychlorodibenzofurans with the lowest LUMO energies. These authors did not see the same relationship with polychlorodibenzodioxins and, by using a magnetic sector instrument, found that metastable processes were contributing to the reduction in intensity of the $[\mathrm{M}]^{-}$ion in the highest chlorinated dioxins examined, namely, 1,2,3,4,6,7,8-hepta- and octa-chlorodibenzo- $p$ dioxins. Erhardt-Zabik et al. [5] also reported that, for a nonachlorobiphenyl and decachlorobiphenyl, the $[\mathrm{M}]^{-}$was not the base peak. However, this does not agree with Stemmler and Hites [17], who reported
[M] as the most intense ion, or with the experience in the authors' laboratory where the $[\mathrm{M}]^{-}$was the base peak for decachlorobiphenyl as well as for all octochlorobiphenyls and nonachlorobiphenyls observed in the analysis of Aroclors or identified in environmentally contaminated samples. Whether metastable processes also occurred in the present work is unknown because of the limitations of the instrumentation used. This subject of increased fragmentation in highly chlorinated PCB requires further research to clarify the question raised by Laramée et al. [13] regarding a strict correlation between electron affinity, LUMO energy, and fragmentation.

Fragmentation is, in part, a function of the amount of energy added to a molecule and the influence of that energy on the ion produced. In ECNCT mass spectrometry, the ionization process is thought to involve the capture of thermal electrons, resulting in the production of negatively charged ions [10]. The energy of these ionizing electrons is therefore important in that the ions produced may or may not then fragment, depending on their ability to stabilize the energy of the attached electron. The average energy of thermal electrons $(\mathrm{E})$ is defined by:

$$
\mathrm{E}=(3 / 2) \mathrm{kT}
$$

where $\mathrm{k}$ is the Boltzman constant and $\mathrm{T}$ is temperature (K). For electrons at $100^{\circ} \mathrm{C}(373 \mathrm{~K})$, the average energy is about $0.05 \mathrm{eV}$. This approximates the energy of the electrons in the source region and therefore the energy acquired by the molecule as it is ionized. The energy of these thermal electrons should be considered with respect to the relationships between orbital energies and between these energies and the number of ortho position chlorine atoms. The LUMO energy decreases less with ortho chlorine number than do the other orbital energies. Thus, when the energy difference between LUMO and LUMO +1 is plotted against the number of ortho chlorine atoms, the energy difference decreases with increasing substitution, as shown in Figure 5. Mean values for the differences for the LUMO-LUMO + 1 energies for each level of ortho chlorination are $-0.49 \mathrm{eV}$ for zero $\mathrm{Cl},-0.32 \mathrm{eV}$ for one $\mathrm{Cl},-0.16 \mathrm{eV}$ for two $\mathrm{Cl},-0.09 \mathrm{eV}$ for three $\mathrm{Cl}$, and $-0.07 \mathrm{eV}$ for four $\mathrm{Cl}$ in the ortho position. For the congeners with three or four ortho position chlorine atoms, the mean energy differences are similar to the $0.05 \mathrm{eV}$ mean energy for thermal electrons in the source. The data presented in this article demonstrate a link between structural characteristics (i.e. twist angle, orbital energies, heats of formation, and the number and position of chlorine atoms) and fragmentation. A question to be asked with respect to these parameters is how much energy must be added to the molecule to cause fragmentation? The observed results show that for the $\mathrm{PCB}$, examined those with the most ortho position chlorine atoms are most prone to fragmentation. In addition, the energy difference between the 
LUMO and LUMO + 1 is similar to the energy of the ionizing electrons. It can, therefore, be suggested that for these $\mathrm{PCB}$, fragmentation begins when the energy of the ionizing electron is more than can be stabilized by the LUMO without raising its energy above that of the LUMO + 1 . This means that by increasing numbers of ortho chlorine atoms, and thus reducing the energy difference between the LUMO and LUMO +1 , the LUMO becomes less able to stabilize a captured electron, and hence fragmentation occurs. This need not be the case for all PCB. For instance, other factors such as the increased electronegativity of the more highly chlorinated PCB may assume greater importance. Precise measurement of the energies required for fragmentation requires equipment specifically designed to produce low energy monoenergetic ionizing electron populations.

The competing effects of the number and position of the substituent chlorine atoms on fragmentation provide an explanation for the observed changes in the pattern of the molecular ion (Table 1) intensities for the 49 PCB congeners examined. The use of molecular modeling reported here provides a more quantitative approach than is possible from empirical observations based only on the spectra. Fragmentation can be linked to quantifiable parameters such as twist angles, heats of formation, and orbital energies and in turn to the number of ortho position chlorine atoms. Molecular models are becoming more efficient and accurate in predicting molecular properties and are approaching the capability of predicting characteristics of reaction transition species such as a PCB molecule containing a captured electron. They may, therefore, eventually provide information that is a practical basis for the prediction of ECNCI mass spectra.

\section{Acknowledgments}

The authors acknowledge Dr. J. J. P. Stewart of the U.S. Air Force Academy, Colorado Springs, Colorado, and Dr. R. Counts from
QCPE for helpful discussions concerning the MOPAC program. This is contribution number 1814 from the Virginia Institute of Marine Science, School of Marine Science, College of William and Mary.

\section{References}

1. Greaves, J.; Harvey, E. Proceedings of the 38th Annual ASMS Conference on Mass Spectrometry and Allied Topics; Tucson, AZ, 1990; pp 659-660.

2. Greaves, J.; Harvey, E.; Macintyre, W. G. Proceedings of the 39th Annual ASMS Conference on Mass Spectrometry and Allied Topics; Nashville, TN, 1991; pp 1584-1585.

3. Greaves, J.; Bekesi, J. G.; Roboz, J. Biomed. Mass Spectrom. $1982,9,106-110$

4. Roos, A. H.; Keinhuis, P. G. M.; Traag, W. A.; Tuinstra, L. G. M. Th. Intern. J. Environ. Anal. Chem. 1989, 36, 155-161.

5. Erhardt-Zabik, S.; Watson, J. T.; Zabik, M. J. Biomed Environ Mass Spectram. 1990, 19, 101-108.

6. Laramée, J. A.; Arbogast, B. C.; Deinzer, M. L. Anal. Chem. 1988, 60, 1937-1943.

7. Guevremont, R.; Yost, R. A.; Jamieson, W. D. Biomed. Environ. Mass Spectrom. 1987, 14, 435-441.

8. Dougherty, R. C. Anal. Chem. 1981, 53, 625-636A.

9. Dougherty, R. C.; Whitaker, M. J.; Smith, L. M.; Stalling, D. L.; Keuhl, D. W. Environ. Health Perspect. 1980, 103-118.

10. Budzikiewicz, H. Mass Spectrom. Rev. 1986, 5, 345-380.

11. Stemmler, E. A.; Hites, R. A. Anal. Chem. 1985, 57, 684692.

12. Stemmler, E. A.; Hites, R. A.; Arbogast, B.; Budde, W. L.; Deinzer, M. L; Dougherty, R. C.; Eichelberger, J. W,; Foltz, R. L.; Grimm, C.; Grimsrud. E. P.: Sakashita, C.; Sears, L. J. Anal. Chem. 1988, 60, 781-787.

13. Laramée, J. A.; Chang, Y.-S.; Arbogast, B. C.; Deinzer, M. L. Biomed. Environ. Mass Spectrom. 1988, 17, 63-67.

14. Montgomery, R. L.; Rossini, F. D. I. Chem. Eng. Data 1978, 23, 125-129.

15. Bastiansen, O.; Scancke, A. Acta Chem. Scand. 1967, 21, 587-589.

16. Sears, L. J.; Campbell, J. A.; Grimsrud, E. P. Biomed. Environ. Mass Spectrom. 1987, 14, 401-415.

17. Stemmler, E. A.; Hites, R. A. Electron Capture Negatioe Ion Mass Spectra of Environmental Conkaminants and Related Compounds. VCH Publisher: New York, 1988. 